\title{
Cisão entre língua, literatura e redação: problemas e perspectivas do ensino da língua
}

\section{Maria Leônia Garcia Costa Carvalho}

Doutora em Letras e Linguística, pelo Programa de PósGraduaçāo em Letras e Linguistica da Universidade Federal de Alagoas; Professora do Departamento de Letras da Universidade Federal de Sergipe.

Resumo: Partindo de resultados de pesquisas sobre o desempenho de alunos do ensino fundamental e médio, este trabalho suscita questionamentos e desenvolve reflexões acerca do papel da escola e do professor de língua materna na contemporaneidade e, ainda, da linguagem e da língua para a vida do ser humano. As ponderaçōes fundamentam-se em autores como Lukács, Bakhtin, Vygotsky, entre outros, que se aprofundaram na compreensão da palavra e, por conseguinte, nas relaçōes que se estabelecem entre os homens. Propōe-se que o docente procure valer-se do ensino da língua para desenvolver, desde o início da aprendizagem, o raciocínio lógico, a ordenação das ideias, as capacidades de interpretação, de reflexão e crítica, a estruturação de textos. Por fim, defende-se que a escola se volte para o mundo experimentado por seus alunos, de forma que a palavra e a linguagem sejam as ferramentas fundamentais para a aquisição e produção do conhecimento, para a harmonia e o entendimento entre as pessoas, para o estabelecimento de critérios de seleção e interpretação das informaçōes que circulam, enfim para uma atuação eficaz no meio em que se vive.

Palavras-chave: ensino de língua; práticas de leitura e escrita; contemporaneidade
Abstract. Based on research results about the performance of students in elementary and secondary education, this work raises questioning and develops reflections about the role of the school and of the native idiom teacher in contemporary, as well as the language and idiom for the human life. These reflections are founded on authors as Lukács, Bakhtin and Vygotsky, among others, which deepened the comprehension of word and the relations established between persons. It proposes that the teacher exploits the idiom teaching in order to develop, since the beginning, the logical comprehension, the ideas ordination, the interpretation capacity, reflection, criticism and the text structuring. Finally, it argues that the school should turn to the world experienced by its students, in such a way that the word and the language can be fundamental tools to the knowledge acquisition and production, to promote harmony and comprehension among the persons, to the development of selection criteria and interpretation of the circulating information, in summary, to have an efficacious performance in the environment where the people live.

Keywords: Idiom teaching; practices of reading and writing; contemporarily. 



\section{Preliminares}

O uso do termo cisão, no título deste artigo, talvez cause certo sobressalto aos leitores. Por que cisão se, hoje em dia, há uma tendência à conjunção de saberes e de disciplinas para melhor compreensão do mundo e do homem? Para melhor esclarecer o tema sobre o qual ora me debruço, faz-se necessária a alusão a certa tendência ainda presente no ensino da língua vernácula: a fragmentação em disciplinas curriculares - Língua Portuguesa, Redação e Literatura - no geral, desde as primeiras séries do ensino fundamental.

Como docente de Língua Portuguesa e Literatura, sempre preocupada com questões pedagógicas, dediqueime a investigações que me apontassem o alcance de atuação das escolas em relação à formação do leitor e do produtor da escrita e os níveis de desempenho dos alunos do ensino fundamental e médio. Mais recentemente, nos primeiros anos desta década, em pesquisas sob minha orientação, patrocinadas pelo PIBIC e FAP ${ }^{1}$, minha curiosidade, como docente da língua vernácula, me levou a averiguar, em escolas públicas e privadas do ensino fundamental, como essas instituições se conduziam em relação à formação do leitor e do produtor da escrita. Algumas inquietações nortearam a investigação, entre elas:

- as ações desenvolvidas para levar os alunos ao domínio das habilidades de leitura e escrita;

- os métodos e técnicas empregados para esse fim;

- as condições oferecidas para incentivar os hábitos de ler e escrever;

- as concepções de língua, leitura e escrita adotadas pelos docentes e pela escola.

Os resultados obtidos com base em pesquisas de campo, através de observações, entrevistas, aplicações de questionários a docentes e discentes, foram bastante reveladores, levando-me a valiosas conclusões, que apontaram o quanto as escolas se têm distanciado da importante meta de preparar alunos para atender às necessidades da vida contemporânea. Os dados coletados
${ }^{1}$ Desenvolvidas nos anos de 2001 a 2004 , a partir do projeto " $\mathrm{A}$ leitura e a escrita nos descaminhos da escola". 
evidenciaram que, nas instituições investigadas, os alunos eram prejudicados:

- pela ausência ou inadequação de ambientes destinados à leitura;

- pela insuficiência ou falta de um acervo apropriado para o desenvolvimento de pesquisas bibliográficas e para a aquisição do hábito e do prazer de ler;

- pela escassez de produções textuais no ambiente escolar;

- pela inexistência de espaços destinados à publicação ou exposição de suas produções escritas (murais, publicações);

- pela utilização de atividades descontextualizadas, sem relação com a realidade do aluno.

A análise das ocorrências registradas, decorrentes da observação das aulas, comprovou os seguintes problemas:

- a excessiva valorização da gramática normativa, através de atividades mecânicas que, utilizando fragmentos da língua e frases soltas, privilegiavam aspectos normativos e descritivos da língua;

- situações de leitura que não desenvolviam a compreensão e o senso crítico dos alunos, nem estimulavam o hábito de ler;

- uso do texto como pretexto para o tratamento de aspectos gramaticais;

- situações de escrita em que predominavam o treino ortográfico, os exercícios gramaticais, a escrita reprodução (cópia, ditado) e não desenvolviam o gosto nem o hábito de escrever;

- raras ocasiões de uso real da língua oral e da escrita em situações pragmáticas.

Em suma, as pesquisas levaram-me a constatar que as instituições investigadas não dispunham de estrutura física, administrativa e pedagógica que garantisse um efetivo ensino-aprendizagem da leitura e 
da escrita. As observações em sala de aula permitiram-me a confirmação de que as práticas escolares relacionadas à disciplina Língua Portuguesa demonstravam pouca ou quase nenhuma preocupação com a formação de leitores e produtores da escrita.

A análise da grade curricular de algumas instituições escolares, por sua vez, ratificou a fragmentação do ensino do idioma, uma vez que "Língua Portuguesa" e "Redação" eram consideradas, na maioria delas, disciplinas autônomas, com professores distintos. Os programas de ensino contemplavam, preferencialmente, a metalinguagem, ou seja, a gramática da língua, não considerando a leitura e a produção de textos como "conteúdos" da disciplina. Em outras instituições, mesmo não ocorrendo tal subdivisão, a lógica da fragmentação permanecia, pois tanto as aulas como os cadernos dos alunos separam gramática, literatura e redação.

Em relação à literatura, também, observou-se uma tendência ao insulamento. O texto literário é tratado isoladamente, como atividade artística com significação própria, independente da leitura do aluno. Não se realça a produção de sentido pelo leitor do texto, a interação entre autor e leitor, as relações entre texto e contexto, o papel formador dessa atividade.

Pondera Rouxel (1996, p. 73) que "a escola ainda cultiva uma visão tradicional de literatura, considerada comoum conjunto de textosa seradmirado, e caracterizada por um bom estilo, digno de ser imitado pelos alunos". Não se respeitam suas peculiaridades, nem se trabalham suas especificidades. Há escolas que recomendam uma série de livros de literatura infantil ou infanto-juvenil, transformando-os em objetos de avaliação (testes ou fichas de leitura com roteiro preestabelecido), ou reduzindo-os a pretextos para estudo da gramática, talvez na tentativa de praticar uma precária integração de conhecimentos, sem dar oportunidade ao aluno de, através da interação com o gênero, construir sentidos, despertar o gosto pela literatura, fazer-se leitor e, até mesmo, produtor de textos. 
Bunzen (2006, p.139), sustentando-se em Kleiman e Moraes, assevera que "este perfil profissional e disciplinar é uma conseqüência evidente da 'pedagogia da fragmentação', que, em vez de favorecer a trans[inter] disciplinaridade, fragmenta as próprias disciplinas em pequenos blocos monolíticos". Sem dúvida, tal atitude é inconcebível em nossos dias, quando se recorre às diversas disciplinas para se atingir um único fim, o conhecimento de forma mais completa. Os Parâmetros Curriculares Nacionais, ao propor os chamados 'temas transversais', sem dúvida, refletem uma tentativa de transcender os paradigmas disciplinares que têm prevalecido até hoje na educação escolar e substituí-los por paradigmas temáticos, interdisciplinares. Assim se manifesta:

A transversalidade diz respeito à possibilidade de se estabelecer na prática educativa, uma relação entre aprender conhecimentos teoricamente sistematizados (aprender sobre a realidade) e as questões da vida real e de sua transformação (aprender na realidade e da realidade). E uma forma de sistematizar esse trabalho é incluílo explícita e estruturalmente na organização curricular, garantindo sua continuidade e aprofundamento ao longo da escolaridade. $\mathrm{Na}$ prática pedagógica, interdisciplinaridade e transversalidade alimentam-se mutuamente, pois o tratamento das questões trazidas pelos Temas Transversais expõe as inter-relações entre os objetos do conhecimento, de forma que não é possível fazer um trabalho pautado na transversalidade tomando-se uma perspectiva disciplinar rígida (BRASIL, 1998, p. 30).

O ensino do vernáculo oferece a possibilidade de trabalhar com temas que envolvam as diversas áreas, tendo-se em vista que a língua dá suporte ao conhecimento historicamente produzido pelos homens, permitindo-lhes estabelecer uma ponte com a realidade. 


\section{Situação da leitura e da escrita}

Os problemas detectados, sem dúvida, refletem-se, de forma direta ou indireta, na aprendizagem da língua. Se os alunos não apresentam a necessária competência em leitura, muito menos a apresentam na escrita. A dificuldade de compreensão de textos tem o mesmo fundamento da dificuldade de expressão: a incapacidade de direcionar processos mentais, portanto, de articular raciocínios, de estruturar linguisticamente sentenças, de ordenar ideias, verificando-se, enfim, a falta do desenvolvimento crítico que envolve não somente textos de outrem, mas os próprios textos.

Em trabalho que produzi anteriormente ${ }^{2}$, já havia feito referências ao desempenho dos vestibulandos da Universidade Federal de Sergipe na prova de redação. Através da apreciação dos textos, cheguei à conclusão que os discentes se apoiaram em particularidades da fala de forma excessiva e não recomendável, sobretudo se consideradas as exigências do Manual do Vestibulando que, além de definir o texto como argumentativo, apontava, como critérios para seu julgamento, a coerência, a coesão e a expressão (domínio do léxico e estrutura da língua).

$\mathrm{Na}$ grande maioria dos textos considerados, verificaram-se problemas não apenas relacionados à expressão (adequação vocabular, ortografia, morfologia, sintaxe, pontuação), mas, sobretudo, à coerência e à coesão (abandono ou afastamento do eixo temático, redundâncias, contradições da ordem lógica, inabilidade em usar conectivos, desarticulação entre segmentos do discurso etc.). Dentre os 700 textos analisados, apenas seis não apresentaram problemas, o que corresponde a $0,86 \%$ deles, portanto uma fração insignificante do total.

Na conclusão da pesquisa, fiz as seguintes considerações:

A simples leitura das redações dos vestibulandos nos revelou a nítida influência da oralidade: omissões, acréscimos e troca de letras; uso de termos e expressões típicos do cotidiano; vícios de concordâncias e regências típicos de variantes 
regionais, além de repetições de palavras e idéias, descontinuidades e envolvimento direto com o interlocutor, entre outras singularidades da língua falada, como se não conseguissem diferenciar a fala da escrita (CARVALHO, 1997).

O resultado de tais avaliações me permitiu inferir que, durante todo o curso fundamental e médio, a escola não conseguiu levar o aluno a organizar seu pensamento, seu raciocínio e, por conseguinte, sua linguagem. Em consequência, as deficiências, os vícios e as dificuldades de leitura e escrita encontradas no ensino fundamental e no médio avançam, apesar de atenuadas, para a universidade e para a vida.

Não tendo o domínio dessas habilidades, tão necessárias ao bom desempenho acadêmico e profissional, os alunos ficam sujeitos a fracassos no mercado de trabalho, não raro, caindo no desemprego ou no subemprego. Também entram na universidade com sérias deficiências que se perpetuam, sobretudo, porque nela, muitas vezes, também vigoram as mesmas práticas escolares. É o que nos fala Marques de Melo:

O estudante não adquiriu o hábito de ler, de buscar subsídios na biblioteca; limita-se às anotações de aula; às apostilas, ao manual único. Não pesquisa, não aprofunda, não cria. Estuda muito menos para a vida do que para os exames (MARQUES DE MELO, 1997, p. 9-18).

Em artigo sobre os indicadores produzidos pelo SAEB, Araújo e Luzio, respectivamente diretor e coordenador de Avaliação da Educação Básica, anotam que os dados obtidos evidenciaram que $42 \%$ dos alunos do terceiro ano do ensino médio se encontram nos estágios "crítico" e "muito crítico" de desenvolvimento de habilidades e competências em língua portuguesa, ou seja, apresentam dificuldades em leitura e interpretação de textos de gêneros variados, estando muito aquém do 
esperado para o final dessa etapa de ensino. Apenas $5 \%$ se encontram na faixa dos considerados "adequados". Além disso, chegaram eles à seguinte constatação:

No Brasil, hoje, temos um enorme contingente de estudantes concluintes no ensino médio, sem preparo para o trabalho, sem condições concretas para ingressarem de forma competente no ensino superior e um enorme desperdício de recursos públicos com a evasão e o abandono (ARAÚJO, LUZIO, 2008).

Sem dúvida, tais palavras retratam uma das grandes questões que têm atormentado não somente os educadores, mas a sociedade como um todo: a ineficácia da escola ante essas questões. Além de não preparar devidamente o indivíduo para ingressar na sociedade como um cidadão participativo e atuante, ela tem condenado à exclusão social muitos infantes e adolescentes, ou seja, indivíduos ainda em fase de formação, que abandonam a escola, seja por não conseguirem passar de ano, seja por ela não atender a suas necessidades mais imediatas, seja por outras razões.

Talvez o termo descompasso seja mais adequado para indicar a situação vivida pelas escolas destinadas à educação básica, diante das grandes e profundas mudanças e das exigências do mundo contemporâneo. A demanda pela leitura e pelo domínio da língua escrita, em nossa sociedade, é cada vez maior. Basta abrir as páginas dos classificados nos jornais para verificar as exigências colocadas aos profissionais à procura de emprego.

Exige-se do candidato que demonstre domínio da língua, não apenas em situações escritas (que apresente uma boa redação, que saiba comunicar-se através de um bom texto), mas também em situações da oralidade (que seja um bom ouvinte e bom falante, tenha a capacidade de interagir com seus interlocutores), além do domínio das denominadas linguagens digitais. Essa demanda não é exclusiva do Brasil, mas é uma questão mundial, já que 
hoje é imprescindível o domínio da escrita como condição para o acesso ao conhecimento e sua produção.

\section{Papel da linguagem na vida do homem}

É válido, aqui, desenvolver uma reflexão acerca da linguagem e da língua para a vida do homem, recorrendo ao pensamento de alguns estudiosos que se preocuparam em dar explicações sobre suas origens e seus papéis.

Conforme Lukács (1997), o ser humano distinguese das demais espécies animais pelo fato de ter a capacidade de fazer uso da linguagem, além de pensar sobre suas ações antes de executá-las, planejando-as, definindo-lhes objetivos, estabelecendo-lhes metas, antecipando-se, assim, ao movimento da realidade. É justamente isto que o diferencia dos outros animais: a prévia ideação, em que o pensamento se associa à ação para atuar sobre a realidade através da linguagem.

Só a partir de um salto ontológico tornou-se possível ao homem desligar-se do condicionamento determinante das ações mecânicas, repetitivas, e tornar-se um ser societário, iniciando, assim, o processo de "humanização" da espécie. A essência desse salto estaria na ruptura com a continuidade normal do desenvolvimento, e não no nascimento da nova fase de ser. Para Lukács, "todo salto implica uma mudança qualitativa e estrutural do ser".

O ser social decorrente dessa mudança ontológica é, portanto, um ser capaz de pensar com objetivos práticos, ou seja, de agir teleologicamente, associando pensamento e ação. O trabalho seria a categoria fundante do novo ser, pois inaugura o indivíduo que, socialmente, é capaz de modificar a natureza de forma consciente e intencional.

Considera ele que uma das consequências diretas do trabalho é o surgimento da relação sujeito-objeto. A distância entre sujeito e objetoéque origina, imediatamente, uma das bases "do ser social dos homens", a linguagem. Entende-se, por isso, que ela é o recurso primeiro para o homem exercer seu domínio sobre o mundo. Esse domínio se exprime em sua percepção e leitura da realidade, sua visão de mundo e sua ação sobre ele: 
O fato simples de que no trabalho se realiza uma posição teleológica é uma experiência elementar da vida cotidiana de todos os homens, tornandose isto um componente ineliminável de qualquer pensamento; desde os discursos cotidianos, até a economia e a filosofia (LUKÁCS, 1997, p.4).

O trabalho, então, serve como mediador entre subjetividade e objetividade, desde que possibilita ao homem a prévia ideação que conduz à ação, e a linguagem serve como âncora de sua atividade mental. Segundo Magalhães...

[...] a percepção da generidade, condição primeira de ser do gênero humano, só é possível através da linguagem que, desde o início, possui as duas finalidades que constituem essa capacidade do ser social: 1) fazer a comunicação entre os seres, sem a qual não há generidade, sendo o sujeito o mediador do discurso; 2) possibilitar o pensar por objetivo - teleologia - sem a qual não há individualidade, sendo o sujeito, aqui, criador do novo - objetos e, inclusive, discurso (MAGALHÃES, 2001, p. 31).

É na relação subjetividade-objetividade que o homem toma consciência de si e do mundo, revelandose de forma objetiva. A linguagem, portanto, reflete a objetividade sob o prisma da subjetividade. É a partir dela que os indivíduos pensam a realidade, tornam-se conscientes dela, o que lhes permite uma efetiva ação sobre ela, que se visualiza em suas práticas sociais e, em especial, em seus discursos.

Os conhecimentos também se produzem através da linguagem, como resultado de ações intersubjetivas decorrentes das atividades coletivas, em que os atos de uns são regulados por outros. Na interação entre diferentes instituições sociais é que o indivíduo aprende e assimila o funcionamento e os usos da língua, habilitando-se a fazer uso dela em diferentes situações. 
Em suas reflexões, Bakhtin (1988, p. 113) assim se manifesta: “A palavra é uma espécie de ponte lançada entre mim e os outros. Se ela se apóia sobre mim em uma extremidade, na outra se apóia sobre o meu interlocutor. A palavra é o território comum do locutor e do interlocutor". Percebe-se que ao tentar definir a palavra, Bakhtin utiliza a metáfora da "ponte", algo que se erige entre dois extremos, o intermédio, o elo necessário. A "ponte", por conseguinte, significa o fundamento, a expressão de seres que dividem um espaço, utilizando um recurso comum e, por isso, constituindo uma relação dinâmica entre identidade e alteridade. A palavra é a mediadora entre o individual e o social, dá concretude ao ato dialógico que, num movimento contínuo, de aproximações e confrontos, permite aos indivíduos a apropriação da realidade.

Ao declarar que "a palavra é território comum do locutor e do interlocutor", o autor tenta explicar a estrutura da enunciação, na qual a palavra não pertence inteiramente ao locutor, desde que ela ocupa uma zona fronteiriça, muito embora lhe caiba uma boa metade, desde que a outra pertence ao interlocutor. Considera, então, Bakhtin que "a situação social mais imediata e o meio social mais amplo determinam completamente e, por assim dizer, a partir do seu próprio interior, a estrutura da enunciação" (Ibidem, p.113). A enunciação nada mais é, portanto, que "o produto da interação de dois indivíduos socialmente organizados”.

A subjetividade, para Bakhtin, também tem uma relação estreita com a palavra. Segundo ele, somente ao mergulhar na "corrente da comunicação verbal", "a consciência desperta e começa a operar" (Ibidem, idem). A consciência, por conseguinte, tem um papel essencial na constituição do sujeito. Originando-se no exercício da comunicação verbal, ela é repleta de signos que traduzem ideologicamente a realidade. $O$ pensador russo vê a linguagem como um produto social e, ademais, razão da atividade mental: "Não é a atividade mental que organiza a expressão, mas, ao contrário, é a expressão que 
organiza a atividade mental que a modela e determina sua orientação" (Ibidem, idem).

O estudo da palavra remete-nos a um aspecto especial de compreensão das relações interativas que os homens efetivam em sociedade. São eles interlocutores reais, cada um com sua postura e um determinado peso na instância da enunciação. A utilização da palavra, como de qualquer outro signo, é inteiramente determinada por essas relações e é resultante de um consenso entre indivíduos socialmente organizados, razão por que é condicionada tanto "pela organização social de tais indivíduos como pelas condições em que a interação acontece" (Ibidem, p. 44).

A compreensão da palavra implica, pois, o entendimento de sua posição como meio de interação de interlocutores reais, cada um com sua postura e um determinado peso na instância da enunciação. Locutor e destinatário têm igual relevância no processo comunicativo: ambos são atuantes na produção da linguagem e fundamentais para a compreensão da realidade social, sendo as diferenças entre eles contingenciais, por razões histórico-sociais.

A palavra, assim, tem um papel essencial nas interações entre os indivíduos, tanto por sua finalidade discursiva, como por constituir "material semiótico da vida interior", a serviço da consciência individual. Por isso, torna-se o meio pelo qual circulam e se definem as formas interpessoais de compreensão e expressão do mundo, desde as atividades mais corriqueiras àquelas que dizem respeito ao conhecimento, à cultura geral e ao comportamento humano. Por conseguinte, a palavra está presente em todos os atos de compreensão e em todos os atos de interpretação. É ela uma referência segura das mudanças sociais, tanto as já estabilizadas, como as que se encontram em curso. Daí sua dupla importância: como instrumento para conhecimento da realidade social e como meio capaz de antecipar mudanças.

Fruto de convenção, portanto, a língua funciona como um recurso social sistematizado para dar curso às 
posições teleológicas, que têm por finalidade levar os homens a agir no meio em que vivem. Por isso, os discursos assumem diferentes sentidos em relação ao lugar histórico e social de onde se fala. Sua compreensão resulta de uma ação dos homens com e sobre a língua, num processo contínuo de apropriação-objetivação da realidade.

A língua dá, enfim, os fundamentos necessários à manifestação do discurso, ou seja, é a possibilidade do discurso, pois todo o sistema linguístico, com seu conjunto de estruturas fonológicas, morfológicas e sintáticas disponíveis, é utilizado pelos falantes em geral, independentemente das condições de sua produção e do momento histórico. Também é pelas atividades de linguagem que o homem se torna sujeito, só por intermédio delas é que tem condições de refletir sobre si mesmo. Por meio das atividades de compreensão e produção de textos, o sujeito desenvolve uma relação íntima com a leitura-escrita.

As ideias dos autores mencionados nos mostram o quanto a linguagem humana foi e continua sendo objeto de reflexões, de questionamentos, de estudos. Para nós, que trabalhamos com a linguagem, que somos alfabetizadores ou professores de língua, é importante retomarmos suas ideias e também refletirmos sobre elas.

Ora, de acordo com Lukács, oagir teleologicamente, isto é, com objetivos preestabelecidos em relação à ação a ser realizada, levou o homem a desenvolver não apenas o pensamento, mas também a linguagem. O homem, desde o início, utilizou a linguagem para atuar sobre seu meio, sobre seus semelhantes. Bakhtin, por sua vez, nos adverte do quanto a linguagem é importante para o desenvolvimento da atividade mental e da consciência individual. Outros estudiosos também atentaram para essas relações, a exemplo de Vygotsky (2000), ao dizer que, embora tenham raízes distintas, em certo período da vida, pensamento e linguagem se cruzam e passam a interagir, exercendo, entre si, influências recíprocas. Tanto a linguagem atua sobre o pensamento, como o pensamento sobre a linguagem. 
Os entendimentos dos autores aqui abordados sobre a linguagem humana despertam questionamentos e perspectivas para o encaminhamento de um efetivo trabalho docente. Por que não tiramos partido da linguagem para ampliar e organizar os processos mentais de nossos discentes, desde o início de sua aprendizagem, através do desenvolvimento do raciocínio lógico, das capacidades de ordenar idéias, de estruturar textos, de reflexão e de crítica? Por que, antes de executar qualquer tarefa, não orientamos os alunos a pensarem sobre ela, a planejarem-se e definirem seus objetivos?

Outra questão que se coloca é a da importância da linguagem nas interações sociais e na apropriação da realidade: não se pode prescindir da presença das pessoas envolvidas no ato linguístico. Em vista disso, a palavra deve ser orientada em função do outro, nosso interlocutor real ou potencial. Deve, pois, sofrer alterações, adaptarse conforme aquele a quem é dirigida, sua posição social, cultural, seu grau de familiaridade, sua aproximação ou distância do grupo em que a palavra é proferida.

$\mathrm{Na}$ escola, essas questões não podem nem devem ser desconsideradas. Desde cedo, é imperioso que as atividades escolares sejam dirigidas a um interlocutor ou interlocutores determinados e que a escola atente para a importância da palavra no estabelecimento das relações sociais, através dos diálogos, das argumentações necessárias à defesa de pontos de vista, de ideias etc. Que se cultive o bom uso da palavra como maior instrumento de harmonia, de boa convivência, pois somente os que não sabem usá-la devidamente apelam para a intolerância!

Segundo os PCN para o ensino fundamental:

O domínio da linguagem, como atividade discursiva e cognitiva, e o domínio da língua como sistema simbólico utilizado por uma comunidade lingüística, são condições de possibilidade de plena participação social. Pela linguagem os homens e as mulheres se comunicam, têm acesso à informação, expressam e defendem pontos de vista, partilham 
e constroem visões de mundo, produzem cultura. Assim, um projeto educativo comprometido com a democratização social e cultural atribui à escola a função e responsabilidade de contribuir para garantir a todos os alunos o acesso aos saberes lingüísticos necessários para o exercício da cidadania (PCN, 1998, p. 19)

Uma escola, desde que comprometida com essa visão, não pode deixar de considerar um aspecto muito importante: as práticas de ensino e de aprendizagem da língua materna devem levar em conta que as práticas de linguagem na sociedade sempre emergem numa visão integradora, em eventos de interação.

Segundo Marti e Coll (2004), a informação é a principal ferramenta da nova sociedade, pois se verifica, em nossos dias, uma rápida e abundante "circulação de informação escrita, audiovisual ou musical e um acesso a elas inimagináveis há apenas alguns anos”, o que nos possibilita o acesso, com grande facilidade, aos arquivos, às bibliotecas virtuais, às filmotecas, às páginas da web, abrindo-nos, por um lado, novas e interessantes possibilidades de conhecimentos e aprendizagens e, por outro, um excesso de informações, o que pode nos conduzir ao caos.

Os signos e os meios em que eles se disponibilizam como mediadores semióticos modificam a maneira de pensar, de memorizar, de relacionarse e, também, de aprender. Integrar-se a suas sistematizações não é a mesma coisa que aprender se apoiando em um texto escrito e em imagens estáticas ou dinâmicas, não apenas pela exigência de uma ou outra tarefa, mas pelo tipo de processos cognitivos que cada sistema solicita, potencializa e impõe à vida. Até mesmo a percepção dos fenômenos modifica, pois ao tempo em que os fatos acontecem, tomamos conhecimento deles (COLL, 2004, p. 420). 
Isso significa que, se por um lado temos maior abundância e rapidez das informações, maior mobilidade espacial e temporal, por outro, "há necessidade de novos processos de apreensão, convivência e circulação dos eventos disponibilizados pelos recursos comunicacionais" (CHIAPPINI, 2001, p.20). O mundo contemporâneo, portanto, requer muito mais de nós e, em consequência, da escola, especialmente de nós, professores de língua e educadores.

Esses aspectos sinalizam uma revolução profunda nas concepções sobre as práticas pedagógicas, uma vez que a escola terá de abandonar, de vez, seu tradicional papel de difusora e controladora do conhecimento, para tornar-se, essencialmente, estimuladora da produção do conhecimento. A informação, antes elemento tão precioso e limitado, hoje é o que há de mais comum e irrestrito, em abundância tal que impõe a seletividade e a crítica, como ferramentas essenciais, a qualquer um que pretenda envolver-se com o conhecimento.

Todavia, por mais que os meios de comunicação deem conta das informações, por mais ágeis e eficazes que sejam...

[...] todos nós sabemos que uma apreensão em maior profundidade dos aspectos mais específicos a determinada área do conhecimento, bem como uma postura investigadora que dê conta da especificidade de certos ângulos do real, só será possível através da leitura (MARIA, 2002).

\section{Considerações finais}

Hoje, torna-se cada vez mais imprescindível que o indivíduo saiba ler e escrever, não apenas de forma mecânica, mas de forma refletida, lúcida, para que consiga agir de modo crítico diante das informações, selecionandoas e correlacionando-as adequadamente, de modo que se faça compreendido pelo outro, afirmando, assim, sua própria autonomia e individualidade, tão importantes que são para sua realização como ser social. 
Para tanto, é necessário que a escola saia do seu casulo e se volte para a realidade que hoje enfrenta, que nada mais é do que o "mundo da vida" dos próprios alunos, em que a abundância da informação é a característica preponderante. A formação de leitores e produtores da escrita é requisito essencial a qualquer atuação eficaz da escola na sociedade.

É decorrente dessa compreensão o que hoje se coloca para a escola: possibilitar ao aluno uma formação que lhe permita compreender criticamente as informações e a realidade social que vivencia, de forma que possa reagir, sabendo, para tanto, organizar sua ação. Para isso, esse aluno precisa apropriar-se do conhecimento e de meios de produção e de divulgação desse conhecimento.

Nas sociedades letradas como a nossa, esse processo de apropriação está estritamente ligado ao conhecimento da língua escrita, principalmente no que se refere à leitura. Esse conhecimento, tal como hoje compreendemos, refere-se a um grau de letramento que inclui tanto saber decifrar o escrito, quanto ler e escrever com proficiência de leitor e escritor competente, enfim, saber utilizar, nas práticas sociais de leitura e escrita, as estratégias e procedimentos que conferem maior fluência e eficácia ao processo de produção e atribuição de sentido aos textos com os quais interagimos.

Não por outras razões, consta nas Orientações Curriculares do Ensino Médio (2007, p. 29):

O que se defende, portanto, é a absoluta necessidade de se avocar e levar adiante o desafio de criar condições para que os alunos construam sua autonomia nas sociedades contemporâneas - tecnologicamente complexas e globalizadas sem que, para isso, é claro, se vejam apartados da cultura e das demandas de suas comunidades. Isso significa dizer que a escola que se pretende efetivamente inclusiva e aberta à diversidade não pode ater-se ao letramento da letra, mas deve, isso sim, abrir-se para os múltiplos letramentos, 
que envolvendo uma enorme variação de mídias, constroem-se de forma multissemiótica e híbrida - por exemplo, nos hipertextos na imprensa ou na internet, por vídeos e filmes etc. Reitera-se que essa postura é condição para confrontar o aluno com práticas de linguagem que o levem a formarse para o mundo do trabalho e para a cidadania com respeito pelas diferenças no modo de agir e de fazer sentido.

Diante dos desafios que se nos apresentam, a educação escolar tem grandes responsabilidades, das quais não se exime o professor, entre elas:

- A definição dos objetivos da escola: que homem se pretende formar?

- Os objetivos da disciplina e do próprio docente (o ensino, sem dúvida, é marcado pela concepção que o professor tem sobre a língua, sobre o homem e a sociedade).

- A importância de se formar o leitor e o produtor da escrita para atender às demandas individuais e sociais. 


\section{Referências}

ARAÚJO, C. H., LUZIO, N. O Desafio do Ensino Médio. Disponível em: <http://www.inep.gov.br/imprensa/artigos/o_ desafio_ensino_médio_i...>. Acesso em: 7 jan. 2008.

BAKHTIN, M. Marxismo e Filosofia da linguagem. São Paulo: Hucitec, 1988.

BARZOTTO, V. H. Os meios de comunicação de massa e os hábitos de leitura. In: (org.). Estado de leitura.

Campinas: Mercado de Letras, 1999.

BRASIL. Parâmetros Curriculares Nacionais: Ensino Fundamental. Brasília: MEC/SEF, 1998.

. Orientaçôes Curriculares para o ensino médio.

Brasília: MEC, 2002.

BUNZEN, C. et al. Português no ensino médio e formação do professor. São Paulo: Parábola editorial, 2006.

CARVALHO, M. L. G. C. Níveis de interferência da oralidade na escrita em redações de vestibular. 1997. Dissertação (Mestrado em Educação) - Universidade Federal de Sergipe, São Cristóvão.

CITELLI, A. O. Educação e mudanças: novos modos de conhecer. In: CITELLI, A. (coord.) Outras linguagens na escola: publicidade, cinema e TV, rádio, jogos, informática. S. Paulo: Cortez, 2001- (Coleção aprender e ensinar com textos; v. 6).

CHIAPPINI, L. A circulação dos textos na escola. In: CITELLI, A. (coord.) Outras linguagens na escola: publicidade, cinema e TV, rádio, jogos, informática. São Paulo: Cortez, 2001(Coleção aprender e ensinar com textos; v. 6)

COLL, C.; MARTI, E. A educação escolar diante das novas tecnologias da informação e da comunicação. In: COLL, C.; MARCHESI, A.; PALACIOS, J. Desenvolvimento Psicológico e educação, 2. Psicologia da Educação Escolar. Porto Alegre: Artmed, 2004. 
LUKÁCS, G. O Trabalho. Tradução de Ivo Tonet. Maceió:
1997 (mimeo).

MAGALHÃES, B. Vidas Secas: Os Desejos de Sinhá Vitória. Curitiba: HD Livros, 2001.

MARIA, L. de, Leitura e colheita: livros, leitura e formação de leitores. Petrópolis, RJ: Vozes, 2002.

MARQUES de MELO. J. Retribalização e decadência da cultura impressa. Revista Estudos Brasileiros (subdesenvolvimento, urbanização e comunicação).

Petrópolis: Vozes, 1997, p. 09-18.

VYGOTSKY, L. S. Pensamento e linguagem. São Paulo:

Martins Fontes, 2000. 